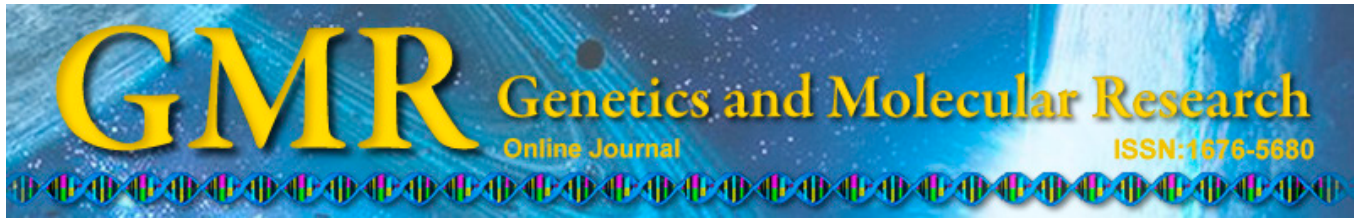

\title{
Molecular and chemical characterization of vetiver, Chrysopogon zizanioides (L.) Roberty, germplasm
}

R.S. Celestino ${ }^{1}$, M.I. Zucchi ${ }^{2}$, J.B. Pinheiro ${ }^{3}$, J.B. Campos ${ }^{2}$, A.A. Pereira ${ }^{3}$, F.G. Bianchini' ${ }^{1}$, R.N. Lima ${ }^{4}$, M.F. Arrigoni-Blank ${ }^{1}$, P.B. Alves ${ }^{4}$ and A.F. Blank ${ }^{1}$

${ }^{1}$ Laboratório de Recursos Genéticos Vegetais e Óleos Essenciais, Departamento de Engenharia Agronômica, Universidade Federal de Sergipe, São Cristóvão, SE, Brasil

${ }^{2}$ Laboratório de Biologia Molecular,

Agência Paulista de Tecnologia dos Agronegócios, Polo Centro Sul, Piracicaba, SP, Brasil

${ }^{3}$ Laboratório de Diversidade Genética e Melhoramento, Departamento de Genética, Escola Superior de Agricultura "Luiz de Queiroz," Universidade de São Paulo, Piracicaba, SP, Brasil ${ }^{4}$ Laboratório de Cromatografia, Departamento de Química, Universidade Federal de Sergipe, São Cristóvão, SE, Brasil

Corresponding author: A.F. Blank

E-mail: afblank@ufs.br

Genet. Mol. Res. 14 (3): 9452-9468 (2015)

Received November 4, 2014

Accepted March 23, 2015

Published August 14, 2015

DOI http://dx.doi.org/10.4238/2015.August.14.9

ABSTRACT. Due to the economic interests in vetiver, Chrysopogon zizanioides (L.) Roberty, molecular and chemical studies are essential to generate information for its sustainable exploitation. The aim of this study was to undertake a molecular and chemical characterization of vetiver accessions of the active germplasm bank of the Universidade Federal de Sergipe. The molecular characteristics of the accessions 
were studied using amplified fragment length polymorphism markers, with a total of 14 primer combinations that generated 442 loci, allowing us to observe that these accessions have similar genomes. The vetiver accessions were divided into three distinct groups, where accession UFS-VET005 was the most differentiated and accession UFS-VET004 had the lowest essential oil content $(0.70 \%)$. The content of the chemical constituents of the essential oils was observed to vary, with a predominance of khusimol, which ranged from 18.97 to $25.02 \%$. It was possible to divide the vetiver accessions into two groups based on chemical composition, and these groups do not correlate with the molecular grouping. Therefore, it is necessary to perform molecular and chemical analyses to characterize vetiver accessions.

Key words: Accessions; Genetic diversity; Chemical diversity; Essential oil; Khusimol

\section{INTRODUCTION}

Vetiver, Chrysopogon zizanioides (L.) Roberty, is a perennial plant from India that belongs to the family Poaceae. It has high economic and social value and is used throughout the world due to its important aromatic, medicinal, and environmental characteristics. Many of the uses of vetiver rely on the essential oil produced in its roots. Essential oils are highly valued by the perfume and cosmetics industries as they are used as fixers and in fragrances, creams, and lotions. Vetiver essential oil also shows important antimicrobial, termiticide, insecticide, and antioxidant activity (Zhu et al., 2001; Kim et al., 2005), in addition to medicinal activity as an anti-hypertensive and diuretic agent (Alencar et al., 2005). The essential oil of vetiver has an aroma with notes ranging from sweet to earthy and woody. It consists of a complex mixture of alcohol sesquiterpenes and low volatility hydrocarbons. The primary producers of this essential oil are Indonesia, China, India, Haiti, and Reunion Island, with an estimated 350 tons produced worldwide in 2012 ( $\mathrm{Lal}, 2013)$.

Plant genetic resources are necessary for the sustainable development of agriculture and agroindustry. For these resources to be correctly preserved, used, and bred, efforts are required in the maintenance, knowledge, and classification of these resources. Thus, molecular and chemical characterization of the germplasm can contribute to the selection of divergent and superior genotypes with greater yields, contents, and concentrations of the substances of interest in the essential oil. Molecular characterization further aids in the evaluation of redundancies and deficiencies of germplasm collections, as it identifies clones and odd individuals, generating information about the efficiency of the collection and maintenance process. This analysis allows for the correct handling of the germplasm bank (Ferreira and Grattapaglia, 1998).

The Universidade Federal de Sergipe (UFS) conducts studies on vetiver, and resources are stored in an active germplasm bank (AGB) with accessions from various locations. However, this bank has not been thoroughly evaluated, and due to the importance of this species, studies are necessary for its correct use.

Therefore, the objective of this study was to perform a molecular (using amplified fragment length polymorphism markers, AFLPs) and chemical evaluation of vetiver germplasm from the AGB at UFS. 


\section{MATERIAL AND METHODS}

\section{Plant material}

To obtain the molecular and chemical data for vetiver, nine accessions from the AGB of UFS were used, located at the Research Farm "Campus Rural da UFS" (latitude $11^{\circ} 00^{\prime} \mathrm{S}$ and longitude $37^{\circ} 12^{\prime} \mathrm{W}$ ), municipality of São Cristóvão, Sergipe State, Brazil (Table 1).

To obtain the material data for the extraction of the essential oil of vetiver, tillers from the nine accessions were transported to Fazenda Deserto of the RAROS Company, which is located in the municipality of Cearamirin-RN-Brazil (latitude $5^{\circ} 38^{\prime} \mathrm{S}$ and longitude $35^{\circ} 26^{\prime} \mathrm{W}$ ) for cultivation.

The experiment was conducted in a random block design with three replications. Each block consisted of a $0.30 \mathrm{~m}$ high and $1.20 \mathrm{~m}$ long furrow containing three lines of vetiver plants. The plants were spaced $0.45 \mathrm{~m}$ apart within each line, and the lines were spaced 0.60 $\mathrm{m}$ apart. The spacing between the furrows was $0.80 \mathrm{~m}$. Each plot consisted of 60 plants. The harvest was performed eight months after planting, on January 17, 2013. The plants were harvested mechanically, and a sample of 10 plants per plot was transported by plane to the Laboratório de Recursos Genéticos e Vegetais e Óleos Essenciais of UFS. Roots were dried in an oven with forced air circulation at $40^{\circ} \mathrm{C}$ for five days.

\begin{tabular}{|c|c|c|c|}
\hline Accession code & Scientific name & Origin & Voucher No. \\
\hline UFS-VET001 & Chrysopogon zizanioides & Raros Company, Natal-RN-Brazil & 13437 \\
\hline UFS-VET002 & Chrysopogon zizanioides & Raros Company, Natal-RN-Brazil & 13504 \\
\hline UFS-VET003 & Chrysopogon zizanioides & Instituto Agronômico de Campinas, Campinas-SP-Brazil & 13505 \\
\hline UFS-VET004 & Chrysopogon zizanioides & Instituto Agronômico de Campinas, Campinas-SP-Brazil & 13506 \\
\hline UFS-VET005 & Chrysopogon zizanioides & Raros Company, Natal-RN-Brazil & 13507 \\
\hline UFS-VET006 & Chrysopogon zizanioides & Federal University of Lavras, Lavras-MG-Brazil & 13508 \\
\hline UFS-VET007 & Chrysopogon zizanioides & Embrapa Recursos Genéticos e Biotecnologia, Brasília-DF-Brazil & 13624 \\
\hline UFS-VET008 & Chrysopogon zizanioides & Embrapa Amazônia Ocidental, Manaus-AM-Brazil & 13625 \\
\hline UFS-VET010 & Chrysopogon zizanioides & Free market, Belém-PA-Brazil & 13627 \\
\hline
\end{tabular}

\section{Molecular characterization using AFLP markers}

To obtain the genetic data for vetiver, young leaves were collected from the nine accessions (one plant/accession). The leaves from each individual were wrapped in moist newspaper, stored in plastic sacks, sealed, and identified. This material was transported to the laboratory, where it was subjected to lyophilization for $48 \mathrm{~h}$ at a pressure of 0.04 millibar and a temperature of $-50^{\circ} \mathrm{C}$. Later, the material was mechanically ground, packed into Falcon tubes, and stored in a freezer at $-20^{\circ} \mathrm{C}$ until DNA extraction was performed. Genomic DNA was extracted using the CTAB protocol (Doyle and Doyle, 1990), with modifications. The DNA was quantified using gel electrophoresis on a 1.0\% agarose gel stained with SYBR Safe (Invitrogen, Carlsbad, CA, USA). The gel products were visualized in a Compact Digimage System (Major Science, Saratoga, CA, USA), with the band intensity compared to the lambda phage DNA standard with concentrations varying from 50 to $300 \mathrm{ng}$.

AFLP analysis was performed according to the protocol described by Vos et al. (1995), with modifications. In the digestion step, $300 \mathrm{ng}$ total DNA, obtained from each individual, was digested in the same reaction with 4 units of the EcoRI (New England BioLabs, Ipswich, 
MA, USA) and MseI (New England BioLabs) restriction endonucleases in $1 \mathrm{X}$ reaction buffer $(50 \mathrm{mM}$ Tris- $\mathrm{HCl}, \mathrm{pH} 8.0$, and $10 \mathrm{mM} \mathrm{MgCl}$ ). The reaction was performed in a thermocycler at $37^{\circ} \mathrm{C}$ for $3 \mathrm{~h}$ followed by incubation at $70^{\circ} \mathrm{C}$ for $15 \mathrm{~min}$. For the ligation reaction, specific adapters were synthesized for the EcoR1 enzyme (Forward: 5'-CTCGTAGACTGCGTACC-3'; Reverse: 5'-AATTGGTACGCAGTCTAC-3') and for MseI (Forward: 5'-GACGATGAGTCCTGAG-3'; Reverse: 5'-TACTCAGGACTCAT-3'), which were diluted to concentrations of $5 \mu \mathrm{M}$ and $50 \mu \mathrm{M}$, respectively. Immediately before use, the adapters were heated to $94^{\circ} \mathrm{C}$ for $2 \mathrm{~min}$. The primers were ligated to the digested DNA in a reaction catalyzed by $T 4$ DNA ligase containing $1 \mathrm{X}$ T4 reaction buffer $(50 \mathrm{mM}$ Tris- $\mathrm{HCl}, 10 \mathrm{mM} \mathrm{MgCl}$, and $10 \mathrm{mM}$ DTT), $1 \mathrm{mM}$ ATP, $1 \mu \mathrm{M}$ of each of the EcoRI and MseI adapters, and 1 unit T4 DNA Ligase. The reaction was performed in a thermocycler at $37^{\circ} \mathrm{C}$ for $2 \mathrm{~h}$ followed by incubation at $16^{\circ} \mathrm{C}$ for $16 \mathrm{~h}$. The reaction products were stored in a freezer at $-20^{\circ} \mathrm{C}$.

The pre-amplification reaction was performed with primers complementary to the adapters for EcoRI and MseI without the addition of selective nucleotides on the 3 ' end $(E c o R I+0$ : 5'-GACTGCGTACCAATTC-3' and MseI+0: 5'-GATGAGTCCTGAGTA A-3'). The reaction was performed in a total volume of $15 \mu \mathrm{L}$, containing $2 \mu \mathrm{L}$ ligation product diluted 6-fold, $1 \mathrm{X}$ PCR buffer $(50 \mathrm{mM} \mathrm{KCl}, 10 \mathrm{mM}$ Tris-HCl, $\mathrm{pH}$ 8.9), 1 unit Taq DNA Polymerase, $0.4 \mathrm{mM}$ of each dNTP, $2 \mathrm{mM} \mathrm{MgCl}, 3.3 \mu \mathrm{M} E c o \mathrm{RI}+0$ primer, and $3.3 \mu \mathrm{M}$ MseI +0 primer. The reactions were performed in a thermocycler programmed to perform 29 cycles of $94^{\circ} \mathrm{C}$ for $30 \mathrm{~s}, 56^{\circ} \mathrm{C}$ for $1 \mathrm{~min}$, and $72^{\circ} \mathrm{C}$ for $1 \mathrm{~min}$. The resulting products were verified on a $1 \%$ agarose gel treated with SYBR Safe. They were later diluted 10 -fold in ultrapure water and stored at $-20^{\circ} \mathrm{C}$.

The selective amplification reaction was performed with primers containing three selective nucleotides on their 3' ends. Four $E c o$ RI +3 primers were marked with fluorophores, of which E- $A A C$ and E- $A C A$ were marked with IRDye 700 (LI-COR Biosciences, Lincoln, Nebraska, USA) and E- $A A G$ and E- $A C C$ were marked with IRDye 800 (LI-COR Biosciences). These reactions had a total volume of $10 \mu \mathrm{L}$, containing $2 \mu \mathrm{L}$ pre-amplified product diluted 10 fold, 1X PCR buffer, 1 unit Taq DNA Polymerase, $0.2 \mathrm{mM}$ of each dNTP, $2.0 \mathrm{mM} \mathrm{MgCl}, 0.5$ $\mu \mathrm{M} E c o \mathrm{RI}+3$ primer, and $1 \mu \mathrm{M} \mathrm{Mse}+3$ primer. The selective amplification program consisted of 13 denaturing cycles at $94^{\circ} \mathrm{C}$ for $30 \mathrm{~s}$, annealing at $65^{\circ} \mathrm{C}$ for $30 \mathrm{~s}$ (with a decrease of $0.7^{\circ} \mathrm{C}$ for each cycle) and extension at $72^{\circ} \mathrm{C}$ for $1 \mathrm{~min}$. Next, 23 cycles were performed at $94^{\circ} \mathrm{C}$ for $30 \mathrm{~s}, 56^{\circ} \mathrm{C}$ for $30 \mathrm{~s}$ and $72^{\circ} \mathrm{C}$ for $1 \mathrm{~min}$. The reactions were performed in a Bio-RAD thermocycler (Bio-RAD, München, Germany).

The amplification products from the AFLP markers were verified in an automatic LI-COR DNA Analyzer 4300 (LI-COR Biosciences) $\left(1500 \mathrm{~V}, 40 \mathrm{~W}, 40 \mathrm{~mA}, 45^{\circ} \mathrm{C}\right.$, running velocity 4$)$ on $25 \mathrm{~cm}$ plates with a $6.5 \%$ polyacrylamide gel matrix KBPLUSTM $(20 \mathrm{~mL}$ polyacrylamide, $15 \mu \mathrm{L}$ TEMED, and $150 \mu \mathrm{L} 10 \%$ ammonium persulfate). A solution containing $2 \mu \mathrm{L}$ bromophenol blue (formamide 90\%) and the IRDye 700 and IRDye 800 fluorophores (LI-COR Biosciences) in a 1:1.5 $\mu \mathrm{L}$ proportion was prepared. This solution was subjected to denaturation at $95^{\circ} \mathrm{C}$ in a thermocycler. For application to the gel, $1 \mu \mathrm{L}$ of each product was used from the selective amplification, with the addition of $3 \mu \mathrm{L}$ bromophenol blue solution. A molecular weight marker was used with fragments between 50 and 700 bp marked with IRDye 700 and IRDye 800 (LI-COR Biosciences). Automatic images of the gels were generated in an electronic format, which were analyzed to obtain the AFLP markers.

For the analysis and interpretation of the gels, only consistent bands were used for each combination of primers. The loci obtained were identified with regard to their presence (1) or absence (0) in each genotype of $C$. zizanioides, with the construction of a binary data 
matrix that was used to perform all of the following analyses.

Genetic variability was estimated using the POPGENE program version 1.31 (Yeh et al., 1999) and quantified using Nei's coefficient (Nei, 1973), assuming that the loci are in Hardy-Weinberg equilibrium due to the dominant nature of the data. The number of observed alleles $\left(N_{\mathrm{A}}\right)$, effective number of alleles $\left(N_{\mathrm{E}}\right)$ (Kimura and Crow, 1964), Nei's genetic diversity $(H)$, Shannon index $(I)$, percentage of polymorphic loci $(P \%)$, total heterozygosity $\left(H_{\mathrm{T}}\right)$, average heterozygosity in the population $\left(H_{\mathrm{s}}\right)$, and divergence coefficient between populations $\left(G_{\mathrm{ST}}\right)$ were used as estimates of genetic variability.

The genetic divergence between pairs of accessions was calculated using the Jaccard index of dissimilarity. Representation of the genetic divergence was performed using a dendrogram obtained through the unweighted pair group method with arithmetic mean (UPGMA) method. Based on this same distance matrix, principal component analysis (PCA) was performed. All of the analyses were undertaken using the program DARwin 5.0 (Perrier and Jacquermoud-Collet, 2006), in which the stability of the groupings was tested through 10,000 bootstrap resamplings using the program BOOD v.3.03 (Coelho, 2000).

STRUCTURE v.2.3.4 (Pritchard et al., 2000a) was used to analyze the population structure of the studied vetiver accessions using a Bayesian approach in which each individual is attributed to groups based on its genotype. $K$ values from 1 to 9 were tested, with nine independent simulations for each grouping with 500,000 iterations. The Evanno et al. (2005) method was used for the selection of the most probable $K$ number. The Clumpp v.1.1.2 program (Jakobsson and Rosenberg, 2007) was also used for verification of the consistency of the $K$ value obtained. From these results, a population structure matrix (Q matrix) that contained the proportion of the genome of each individual with an origin in some of the $K$ (subgroups) identified was obtained.

\section{Chemical characterization}

The extraction of the essential oil was performed by hydrodistillation using the Clevenger apparatus (Guenther, 1972). Each sample was composed of $50 \mathrm{~g}$ of dried roots, with a distillation time of $180 \mathrm{~min}$ according to the protocol used by Massardo et al. (2006). The concentrations (\%) were estimated based on the volume/dry mass of the roots.

For the chemical analysis of the essential oils, a Gas Chromatograph - Mass Spectrometer with a Flame Ionization Detector (GC-MS/FID) was used (GC-2010 Plus; GC/MSQP2010 Ultra) (Shimadzu Corporation, Kyoto, Japan) equipped with an AOC-20i automatic sampler (Shimadzu Corporation). The separations were performed using an Rtx ${ }^{\circledR}-5 \mathrm{MS}$ Restek fused-silica capillary column (polysiloxane 5\%-diphenyl-95\%-dimethyl) $30 \mathrm{~m}$ x $0.25 \mathrm{~mm}$ internal diameter (i.d.) and a $0.25 \mu \mathrm{m}$ film thickness in a constant flow of helium (99.999\%) with a flow rate of $1.2 \mathrm{~mL} / \mathrm{min}$. An injection volume of $0.5 \mu \mathrm{L}$ was used $(5 \mathrm{mg} / \mathrm{mL})$, with a split ratio of $1: 10$. The programming of the oven temperature started at $50^{\circ} \mathrm{C}$ (isothermal for 1.5 min), with an increase of $4^{\circ} \mathrm{C} / \mathrm{min}$ to $200^{\circ} \mathrm{C}$, followed by an increase of $10^{\circ} \mathrm{C} / \mathrm{min}$ to $250^{\circ} \mathrm{C}$, finishing with an isotherm of $5 \mathrm{~min}$ at $250^{\circ} \mathrm{C}$.

The MS and FID data were acquired simultaneously using a detector separation system; the split flow ratio was 4:1 (MS:FID). A restrictor tube of $0.62 \mathrm{~m} \times 0.15 \mathrm{~mm}$ i.d. (capillary column) was used to connect the divider to the EM detector; a restrictor tube of $0.74 \mathrm{~m} \times 0.22 \mathrm{~mm}$ i.d. was used to connect the divider to the FID detector. The injector temperature was $250^{\circ} \mathrm{C}$, and the ion generator temperature was $200^{\circ} \mathrm{C}$. The mass spectra were 
generated at $70 \mathrm{eV}$; a confirmation sweeping velocity of $0.3 \mathrm{~s}$ was used, and the fragments were detected in the range of 40 to $350 \mathrm{Da}$. The FID temperature was adjusted to $250^{\circ} \mathrm{C}$, and the gases supplied to the FID were synthetic air, hydrogen, and helium at flow rates of 30,300 , and $30 \mathrm{~mL} / \mathrm{min}$, respectively. The quantification of each constituent was estimated by the normalization of the area of the peak generated in the FID (\%). The concentrations of the compounds were calculated from the areas of the GC peaks and were arranged in order of elution.

The constituents of the essential oil were identified by the comparisons of their mass spectra with existing spectra in the literature (Adams, 2007), with spectra from the databank (NIST21 and NIST107) of the equipment, and through comparisons of the retention indices with those in the literature. The relative retention indices were determined with a homologous series of n-alkanes (C8-C18) injected in the same chromatographic conditions as the samples using the Van Den Dool and Kratz (1963) equation.

An analysis of variance was performed, and the means were compared with the ScottKnott Test $(\mathrm{P}<0.05)$ using the SISVAR 5.3 software (Ferreira, 2010).

The data from the chemical composition were analyzed using PCA in the Statistica 7.0 software.

\section{RESULTS}

\section{Molecular analyses with AFLP markers}

A total of 26 combinations of the $E c o \mathrm{RI}+3$ and $M s e \mathrm{I}+3$ primers were tested on nine genotypes from the vetiver AGB at UFS. Taking into consideration the combinations that showed the best pattern of consistent loci, to avoid ambiguity, a total of 14 combinations of AFLP primers were selected for the study, generating a total of 442 loci, of which 169 were monomorphic and 273 were polymorphic, with an average of 19.5 loci/polymorphic primer. This result corresponds to the degree of polymorphism of $61.76 \%$ between the evaluated accessions of C. zizanioides.

Differences were observed between the amplification patterns for the different combinations tested, with the number of loci varying from 19 (4.30\%; E-ACA/M-CTA) to 50 (11.31\%; E-AAC/M-CAG), with an average of 31.57 loci per combination. Lerceteau and Szmidt (1999) reported a direct relationship between the numbers of $\mathrm{A} / \mathrm{T}$ and $\mathrm{G} / \mathrm{C}$ bases of the primers and the total number of loci obtained for Pinus sylvestris. The number of $\mathrm{G} / \mathrm{C}$ bases in the primers was inversely proportional to the number of bands obtained on the gel. This relationship was not found in vetiver as it was not possible to correlate the variation in the number of loci with the nucleotide composition of the species because primer combinations with different nucleotide compositions generated similar numbers of bands on the gel. The primer combinations were named according to the code of the selective primers for EcoRI and MseI (Table 2).

Figure 1 illustrates the electrophoretic profile of the AFLP markers from the test of different combinations performed on the nine vetiver individuals from the AGB at UFS, which was generated using the LI-COR automatic DNA analyzer (LI-COR Biosciences). The weak bands and those that generated doubts in the analysis were not considered in this study.

The genetic variation index, obtained from the AFLP loci, was related to $N_{\mathrm{E}}$ and $N_{\mathrm{A}}$, and the heterozygosity permitted confirmation that the average $N_{\mathrm{A}}$ was 1.62 and the average $N_{\text {E }}$ that contributed to the genetic diversity was 1.51 (Table 3 ). 
Table 2. Total number of loci and number of polymorphic loci generated with the 14 combinations of amplified fragment length polymorphism primers (EcoRI +3 and Mse I +3$)$ in nine Chrysopogon zizanioides accessions from the active germplasm bank at the Universidade Federal de Sergipe, Brazil.

\begin{tabular}{rccc}
\hline No. & Combination of primers & No. of markers & No. of polymorphic markers \\
\hline 1 & AAC/CAG & 50 & 38 \\
2 & AAC/CAT & 46 & 21 \\
3 & AAG/CAC & 24 & 11 \\
4 & AAG/CAT & 29 & 16 \\
5 & AAG/CTC & 32 & 26 \\
6 & AAG/CTG & 35 & 21 \\
7 & ACA/CAA & 33 & 17 \\
8 & ACA/CAT & 24 & 19 \\
9 & ACA/CTA & 19 & 10 \\
10 & ACA/CTG & 21 & 12 \\
11 & ACC/CAC & 20 & 9 \\
12 & ACC/CAT & 34 & 23 \\
13 & ACC/CTA & 31 & 28 \\
14 & ACC/CTC & 44 & 22 \\
& Total & 442 & 273 \\
\end{tabular}

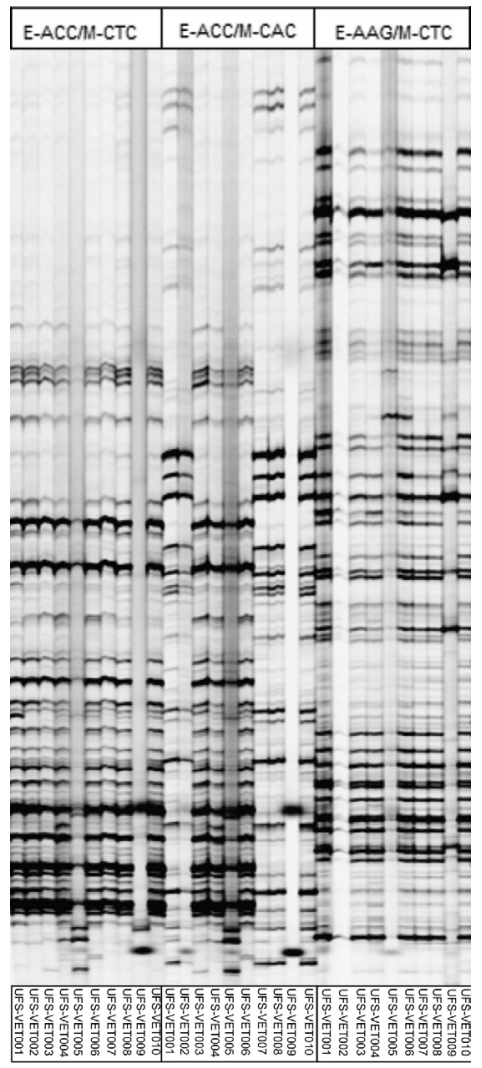

Figure 1. Electrophoretic profiles of amplified fragment length polymorphism fragments in acrylamide gels, generated using the automatic DNA analyzer LI-COR 4300 (LI-COR) for nine Chrysopogon zizanioides accessions from the active germplasm bank of the Universidade Federal de Sergipe. Letters at the top of the figure denote primer combinations. 
Table 3. Estimates of the genetic variability for the 442 AFLP loci in the nine Chrysopogon zizanioides accessions from the active germplasm bank at the Universidade Federal de Sergipe, Brazil.

\begin{tabular}{lrc}
\hline Parameter & Value & Standard Deviation \\
\hline Number of observed alleles $\left(N_{\mathrm{A}}\right)$ & 1.62 & 0.49 \\
Number of expected alleles $\left(N_{\mathrm{E}}\right)$ & 1.51 & 0.35 \\
Nei's genetic diversity index $(H)$ & 0.21 & 0.19 \\
Shannon's index $(I)$ & 0.32 & 0.27 \\
Polymorphic loci $(P \%)$ & 61.76 & - \\
\hline
\end{tabular}

Heterozygosity $(H)$ or Nei's genetic diversity index is a measure of genetic variability that estimates how much variation exists between related individuals and how this variation is distributed in each polymorphic locus. In this study, a value of 0.21 was obtained for the nine evaluated vetiver accessions (Table 3 ). This value indicates homozygosity in the genotypes and is close to the value found by Netto et al. (2004) for AFLP analyses of accessions of Zea mays $(H=0.28)$.

To estimate the genetic relationships between the $C$. zizanioides accessions, a matrix of dissimilarity was constructed (Table 4) by adopting the Jaccard coefficient, which was used for the preparation of the dendrogram using the UPGMA grouping method, with reliability of the branches evaluated via resampling of 10,000 bootstraps (Figure 2). The Jaccard coefficient is one of the most commonly used methods in the analysis of diversity as it is easy to comprehend and is the most recommended for comparing intraspecific genotypes using data from dominant markers (Mohammadi and Prasanna, 2003; Meyer et al., 2004).

The coefficient of dissimilarity used to calculate the genetic divergence between the nine vetiver accessions evaluated from the AFLP markers varied from 0.04 to 0.61 , with an average of $0.24 \pm 0.01$ (Table 4), indicating that the studied set of accessions exhibit genetic diversity.

Table 4. Genetic dissimilarity estimated by the Jaccard coefficient between nine Chrysopogon zizanioides accessions from the active germplasm bank at the Universidade Federal de Sergipe, Brazil.

\begin{tabular}{|c|c|c|c|c|c|c|c|c|c|}
\hline Accession & $\begin{array}{c}\text { UFS- } \\
\text { VET001 }\end{array}$ & $\begin{array}{c}\text { UFS- } \\
\text { VET002 }\end{array}$ & $\begin{array}{c}\text { UFS- } \\
\text { VET003 }\end{array}$ & $\begin{array}{c}\text { UFS- } \\
\text { VET004 }\end{array}$ & $\begin{array}{c}\text { UFS- } \\
\text { VET005 }\end{array}$ & $\begin{array}{c}\text { UFS- } \\
\text { VET006 }\end{array}$ & $\begin{array}{c}\text { UFS- } \\
\text { VET007 }\end{array}$ & $\begin{array}{c}\text { UFS- } \\
\text { VET008 }\end{array}$ & $\begin{array}{c}\text { UFS- } \\
\text { VET010 }\end{array}$ \\
\hline UFS-VET001 & - & & & & & & & & \\
\hline UFS-VET002 & 0.14 & - & & & & & & & \\
\hline UFS-VET003 & 0.22 & 0.25 & - & & & & & & \\
\hline UFS-VET004 & 0.18 & 0.19 & 0.13 & - & & & & & \\
\hline UFS-VET005 & 0.55 & 0.55 & 0.51 & 0.53 & - & & & & \\
\hline UFS-VET006 & 0.19 & 0.17 & 0.14 & 0.11 & 0.61 & - & & & \\
\hline UFS-VET007 & 0.11 & 0.12 & 0.17 & 0.13 & 0.53 & 0.11 & - & & \\
\hline UFS-VET008 & 0.12 & 0.13 & 0.17 & 0.14 & 0.53 & 0.13 & 0.04 & - & \\
\hline UFS-VET010 & 0.17 & 0.21 & 0.22 & 0.18 & 0.53 & 0.18 & 0.11 & 0.12 & - \\
\hline
\end{tabular}

Based on the matrix of dissimilarity, it was verified that the accessions UFS-VET005 (Natal-RN) and UFS-VET006 (Lavras-MG) were the most divergent at 0.61. In contrast, the accessions UFS-VET007 (Cenargen-DF) and UFS-VET008 (Embrapa-AM) were the most similar, with a genetic divergence of only 0.04 (Table 4).

Through the analysis of the dendrogram using the UPGMA method, it was possible to verify the grouping of the C. zizanioides individuals into three principal groups with $100 \%$ consistency for the nodes formed. The accession UFS-VET005 was shown to be the most divergent relative to the majority of the genotypes (Figure 2).

Group A consisted of the accessions UFS-VET001 (Raro's Natal-RN), UFS-VET002 
(Raro's Natal-RN), UFS-VET007 (Cenargen-DF), UFS-VET008 (Embrapa-AM), and UFSVET0010 (Belém-PA). This group was shown to be similar, with the greatest divergence for the accession from Pará, Brazil. Accessions from Haiti produce essential oil that is highly valued on the commercial market (Chomchalow and Chapman, 2003), and in general, all of the accessions placed in Group A are used to obtain a commercial product, as is the case for the accession UFS-VET001 (Raro's Agroindústria) and those from Embrapa (Brazilian Enterprise for Agricultural Research).

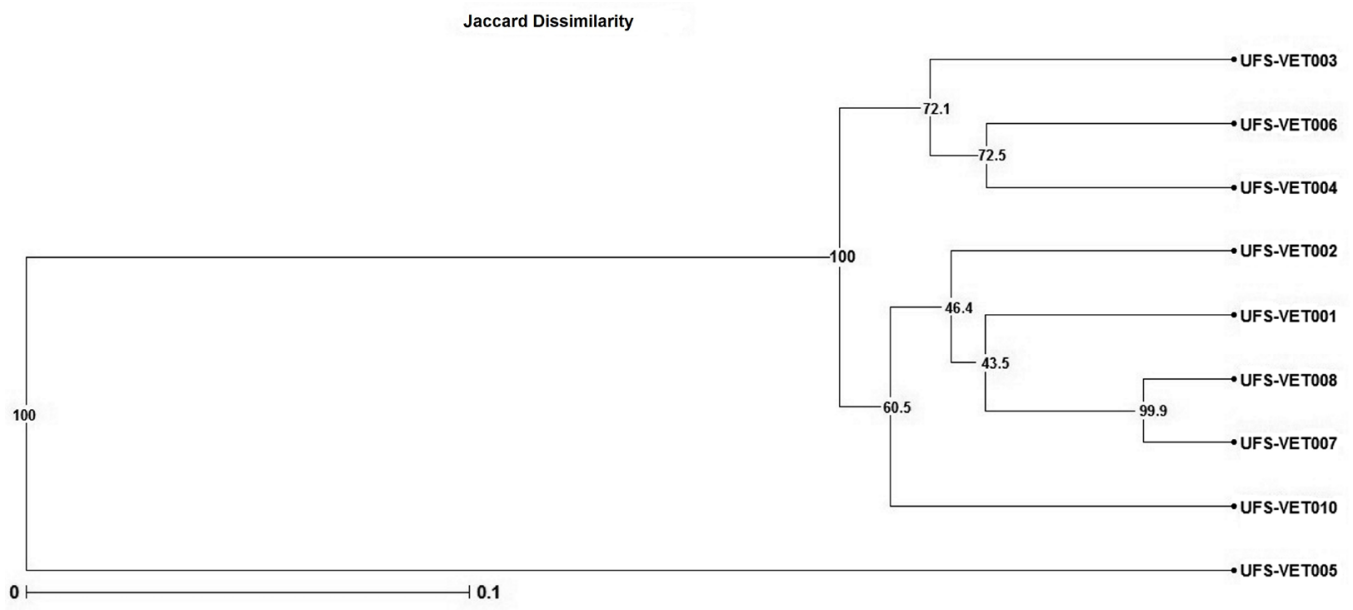

Figure 2. Dendrogram based on Jaccard's dissimilarity index, with unweighted pair group method with arithmetic mean clustering method, for nine Chrysopogon zizanioides accessions from the active germplasm bank at the Universidade Federal de Sergipe, Brazil, based on 442 bands (amplified fragment length polymorphism) from 14 primer combinations. The values next to the branch divisions represent stability, tested by resampling 10,000 bootstraps.

The second group (Group B) consisted of the accessions UFS-VET003 (IAC-SP), UFS-VET004 (IAC-SP), and UFS-VET006 (Lavras-MG) with 72\% consistency. The accession UFS-VET003 produces a Bourbon type oil, which is characterized as being rich in constituents of high interest to the perfume industry. This accession/variety showed an average distance of $13.5 \%$ relative to the other accessions in the same group, showing a relative degree of relatedness. However, as it involves a secondary metabolite, the chemical composition of vetiver may be intimately related to environmental factors. Group C consisted of only one individual, UFS-VET005 (Natal-RN), as it had the largest difference among the evaluated individuals.

According to Meyer et al. (2004), the use of various grouping methods prevents incorrect inferences from being adopted in the distribution of materials within a specific group of genotypes due to the differences in the hierarchy and ordering of groups. Thus, the grouping analysis using the UPGMA method based on the Jaccard coefficient showed agreement with the formation of three groups (Figure 3).

The bar graph resulting from the Bayesian analysis performed with the STRUCTURE program with $\mathrm{K}=3$ is shown in Figure 4. 


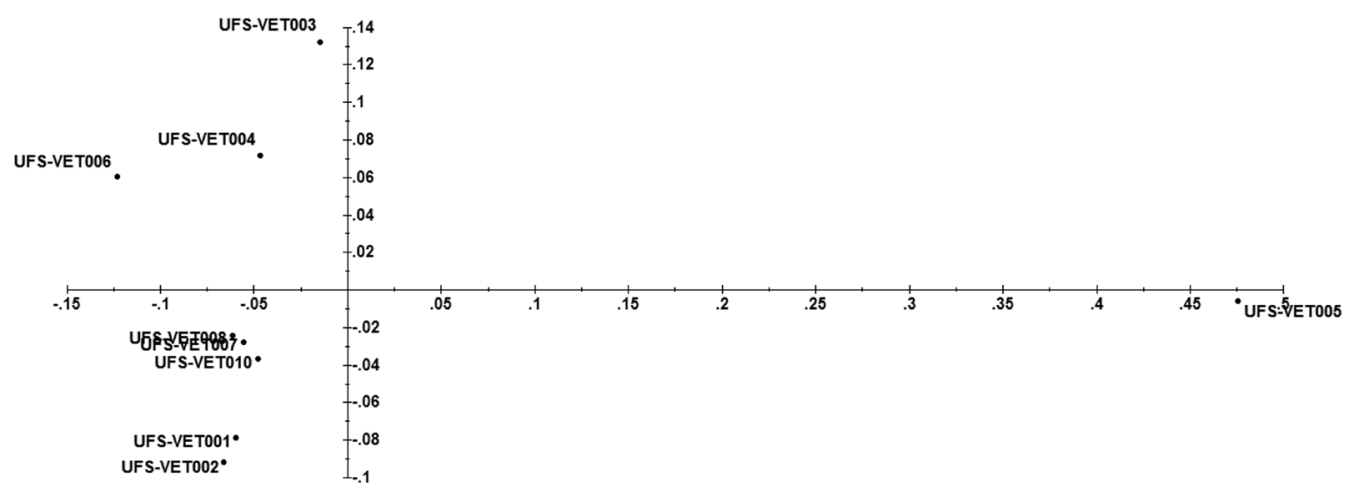

Figure 3. Principal component analysis of nine Chrysopogon zizanioides accessions from the active germplasm bank at the Universidade Federal de Sergipe, Brazil, using amplified fragment length polymorphism markers, based on the arithmetic complement of the Jaccard index.

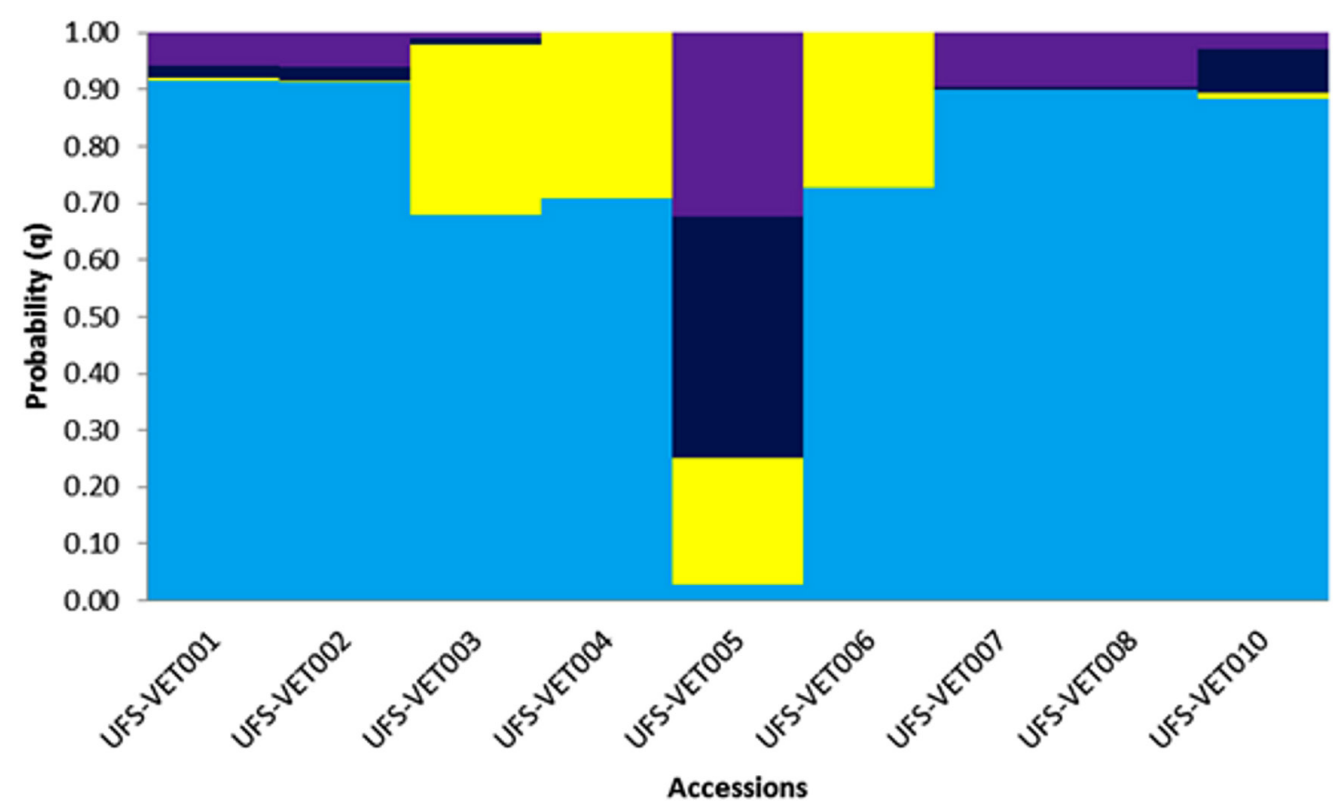

Figure 4. Genetic structure of nine Chrysopogon zizanioides accessions from the active germplasm bank at the Universidade Federal de Sergipe, Brazil, using 442 amplified fragment length polymorphism markers. Different colors for the same individual indicate the probability of membership (q) of that accession to each group. $K=3$.

\section{Chemical characterization of the essential oil}

The chemical composition of the essential oil of the vetiver accessions showed predominantly sesquiterpenes. Of the compounds present in the essential oil of the nine accessions, seven primary constituents were identified (Table 5), and among these, significant differences were observed between vetiver accessions for the compounds vetiselinenol and isovalencenol (Table 5). 
Table 5. Content and main chemical compounds present in the essential oil of Chrysopogon zizanioides accessions from the active germplasm bank at the Universidade Federal de Sergipe, Brazil.

\begin{tabular}{lcccccccc}
\hline Accessions & Essential oil content (\%) & kusimone & valerianol & (epi)-zinzazone & vetiselinenol & khusimol & isovalencenol & $\alpha$-vetivone \\
\hline RRI* & - & 1613 & 1665 & 1680 & 1738 & 1760 & 1807 & 1861 \\
UFS-VET001 & $1.33^{\mathrm{a}}$ & $3.84^{\mathrm{a}}$ & $3.83^{\mathrm{a}}$ & $4.43^{\mathrm{a}}$ & $7.61^{\mathrm{a}}$ & $18.97^{\mathrm{a}}$ & $7.79^{\mathrm{a}}$ & $9.18^{\mathrm{a}}$ \\
UFS-VET002 & $1.20^{\mathrm{a}}$ & $3.84^{\mathrm{a}}$ & $2.70^{\mathrm{a}}$ & $4.53^{\mathrm{a}}$ & $7.30^{\mathrm{a}}$ & $21.58^{\mathrm{a}}$ & $6.93^{\mathrm{a}}$ & $10.58^{\mathrm{a}}$ \\
UFS-VET003 & $1.40^{\mathrm{a}}$ & $4.36^{\mathrm{a}}$ & $3.50^{\mathrm{a}}$ & $5.09^{\mathrm{a}}$ & $6.96^{\mathrm{a}}$ & $22.05^{\mathrm{a}}$ & $4.62^{\mathrm{b}}$ & $9.74^{\mathrm{a}}$ \\
UFS-VET004 & $0.70^{\mathrm{b}}$ & $5.12^{\mathrm{a}}$ & $3.72^{\mathrm{a}}$ & $6.58^{\mathrm{a}}$ & $5.77^{\mathrm{a}}$ & $22.87^{\mathrm{a}}$ & $3.16^{\mathrm{b}}$ & $7.45^{\mathrm{a}}$ \\
UFS-VET005 & $1.40^{\mathrm{a}}$ & $4.20^{\mathrm{a}}$ & $3.81^{\mathrm{a}}$ & $4.93^{\mathrm{a}}$ & $6.96^{\mathrm{a}}$ & $20.83^{\mathrm{a}}$ & $6.51^{\mathrm{a}}$ & $9.08^{\mathrm{a}}$ \\
UFS-VET006 & $1.46^{\mathrm{a}}$ & $4.20^{\mathrm{a}}$ & $3.98^{\mathrm{a}}$ & $4.99^{\mathrm{a}}$ & $6.10^{\mathrm{a}}$ & $21.46^{\mathrm{a}}$ & $5.74^{\mathrm{a}}$ & $9.13^{\mathrm{a}}$ \\
UFS-VET007 & $1.26^{\mathrm{a}}$ & $4.83^{\mathrm{a}}$ & $2.95^{\mathrm{a}}$ & $5.65^{\mathrm{a}}$ & $4.63^{\mathrm{b}}$ & $25.02^{\mathrm{a}}$ & $4.95^{\mathrm{b}}$ & $8.01^{\mathrm{a}}$ \\
UFS-VET008 & $1.33^{\mathrm{a}}$ & $4.26^{\mathrm{a}}$ & $3.94^{\mathrm{a}}$ & $5.66^{\mathrm{a}}$ & $6.21^{\mathrm{a}}$ & $21.59^{\mathrm{a}}$ & $6.48^{\mathrm{a}}$ & $7.46^{\mathrm{a}}$ \\
UFS-VET010 & $1.20^{\mathrm{a}}$ & $5.16^{\mathrm{a}}$ & $3.82^{\mathrm{a}}$ & $5.12^{\mathrm{a}}$ & $5.67^{\mathrm{a}}$ & $24.38^{\mathrm{a}}$ & $3.76^{\mathrm{b}}$ & $7.99^{\mathrm{a}}$ \\
CV $(\%)$ & 16.79 & 18.34 & 24.28 & 16.39 & 15.83 & 17.88 & 27.03 & 17.28 \\
\hline
\end{tabular}

Values with the same letters in the columns do not differ by the Scott-Knott test $(\mathrm{P} \leq 0.05) .{ }^{*} \mathrm{RRI}=$ Relative Retention Index. CV = Coefficient of variation.

The accession UFS-VET007 showed a lower concentration of vetiselinenol (4.63\%) relative to the other accessions (Table 5). Similar results were found by Champagnat et al. (2006) when they evaluated the chemical composition of the essential oil of vetiver from different locations, revealing a percentage of $7.8 \%$ for the compound vetiselinenol.

For isovalencenol, the highest concentrations were observed for the accessions UFSVET001 (7.79\%), UFS-VET002 (6.93\%), UFS-VET005 (6.51\%), UFS-VET008 (6.48\%), and UFS-VET006 (5.74\%). Different results were also observed for this constituent by Massardo et al. (2006) when they evaluated the differences in the essential oil composition of vetiver at different stages of plant growth, finding 49 components in total, of which isovalencenol represented $23.7 \%$.

The compound khusimol, one of the compounds of economic importance from the essential oil of vetiver, showed the highest concentration in the accessions evaluated, varying from 18.97 to $25.02 \%$, demonstrating the fitness of the accessions for commercial production.

Among the chemical compounds of the essential oil of vetiver, khusimol, isovalencenol, and $\alpha$-vetivone are the primary constituents; these chemical compounds are considered the fingerprint of the essential oil (Kim et al., 2005).

Based on the chemical analyses, the compounds found in the greatest quantities in the essential oil of vetiver permit the nine accessions studied to be assigned to two different groups, which are shown in Figure 5. Considering the dissimilarities of the chemical constituents, the groupings were characterized as follows: Group 1, consisting of the accessions UFS-VET001, UFS-VET002, UFS-VET003, UFS-VET005, and UFS-VET008, with the major components being valerianol, vetiselinenol, isovalencenol, and $\alpha$-vetivone, and Group 2, consisting of the accessions UFS-VET004, UFS-VET007, and UFS-VET010, with the major components being khusimone, (epi)-zinzazone, and khusimol (Figure 6).

Based on the PCA for the chemical constituents of the vetiver essential oil (Figure 7), the primary principal component represents $65.57 \%$ of the total information and is positively correlated with vetiselinenol $(\mathrm{r}=0.91)$ and valerianol $(\mathrm{r}=0.06)$ and negatively correlated with (epi)-zinzazone $(\mathrm{r}=-0.82)$ and khusimone $(\mathrm{r}=-0.95)$. The secondary principal component represents $20.27 \%$ of the total information, and is positively correlated with isovalencenol $(r=$ $0.88)$ and $\alpha$-vetivone $(\mathrm{r}=0.73)$ and negatively correlated with khusimol $(\mathrm{r}=-0.90)$ (Figure 7). PCA also allowed for the detection of the characteristics that most strongly contribute to the groupings and the correlation between these characteristics. 


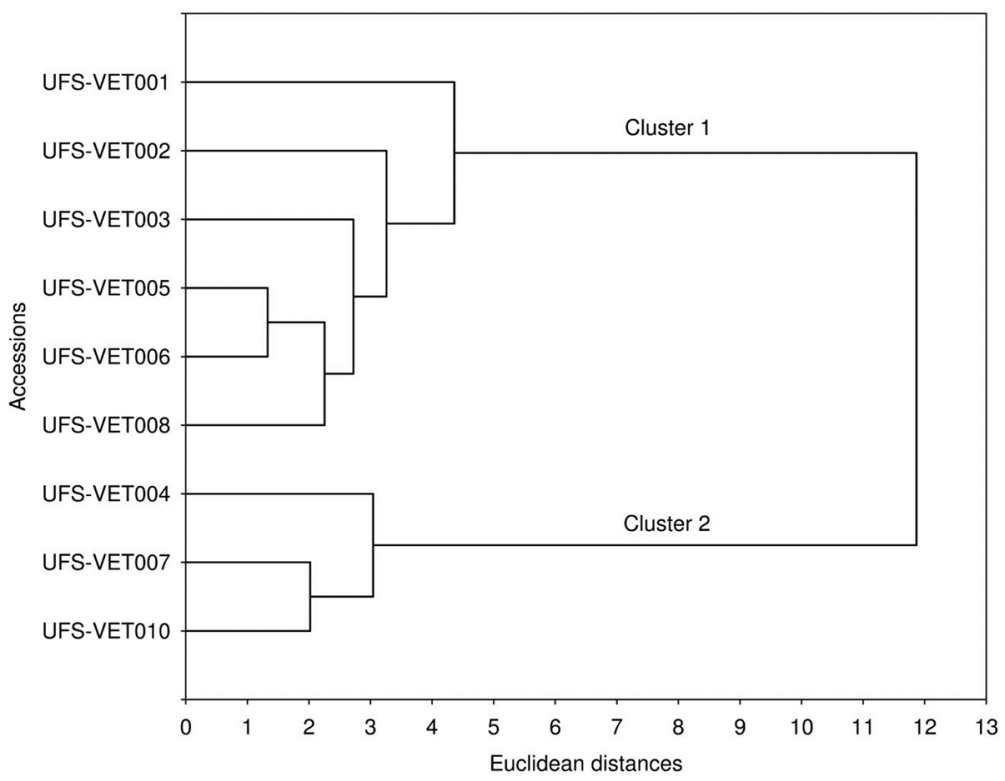

Figure 5. Bi-dimensional dendrogram representing the similarity of nine Chrysopogon zizanioides accessions from the active germplasm bank at the Universidade Federal de Sergipe, Brazil, based on the chemical composition of the essential oil.
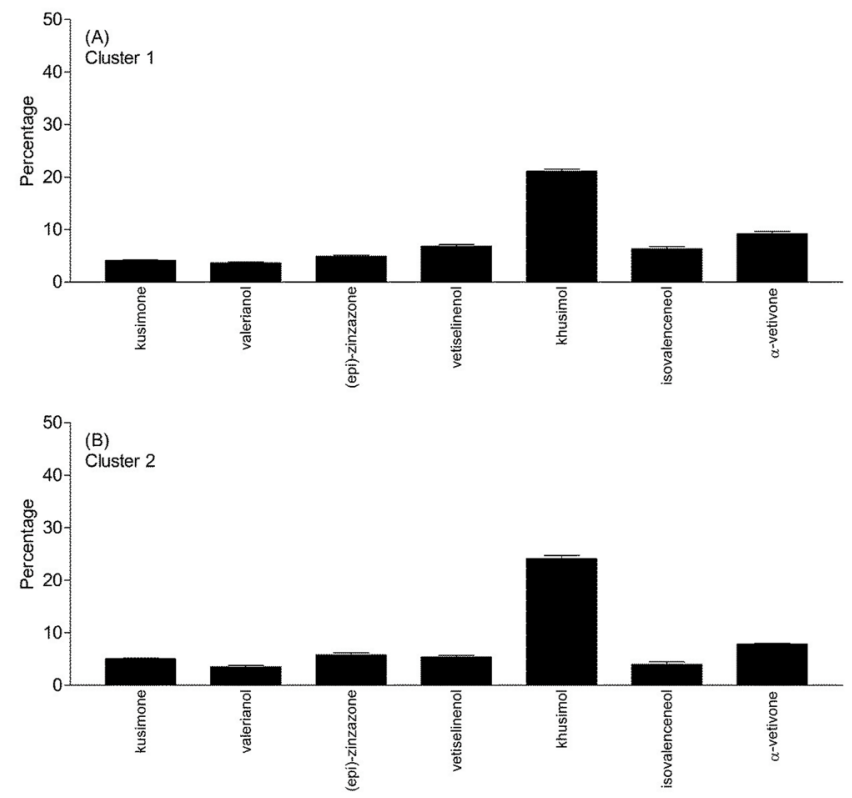

Figure 6. Mean chemical composition of the essential oil of clusters I (A) and II (B) of nine Chrysopogon zizanioides accessions from the active germplasm bank at the Universidade Federal de Sergipe, Brazil (means $\pm \mathrm{SE}$ ). 


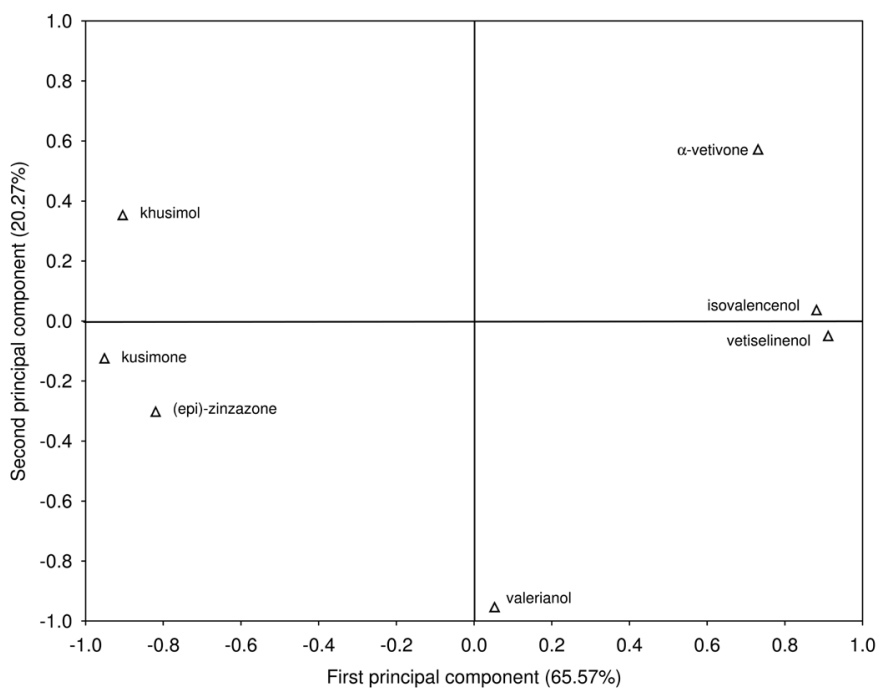

Figure 7. Principal component analysis of the chemical constituents of the essential oil of nine Chrysopogon zizanioides accessions from the active germplasm bank at the Universidade Federal de Sergipe, Brazil.

A correlation greater than 0.50 was observed between some chemical constituents of the vetiver essential oil in the evaluated accessions (Table 6). The correlation between khusimol and khusimone (0.83) was strong and positive, indicating that these constituents of the essential oils of all of the vetiver accessions are intimately correlated.

The compounds (epi)-zinzazone and $\alpha$-vetivone, as well as khusimone and (epi)-zinzazone, showed coefficients of correlation of 0.79 and 0.74 (strong), respectively. Vetiselinenol and isovalencenol showed significant differences between the accessions and had a moderate and positive correlation (0.66). The majority of the constituents showed coefficients of correlation classified as moderate, which signifies average correlation between the studied variables.

Table 6. Correlation coefficients for the main chemical constituents of the essential oil of the Chrysopogon zizanioides accessions from the active germplasm bank at the Universidade Federal de Sergipe, Brazil.

\begin{tabular}{|c|c|c|c|c|c|c|c|}
\hline Compound & kusimone & valerianol & (epi)-zinzazone & vetiselinenol & khusimol & isovalencenol & $\alpha$-vetivone \\
\hline kusimone & 1.00 & & & & & & \\
\hline valerianol & 0.11 & 1.00 & & & & & \\
\hline (epi)-zinzazone & 0.74 & 0.13 & 1.00 & & & & \\
\hline vetiselinenol & -0.79 & 0.08 & -0.68 & 1.00 & & & \\
\hline khusimol & 0.83 & -0.34 & 0.54 & -0.88 & 1.00 & & \\
\hline isovalencenol & -0.93 & -0.06 & -0.72 & 0.66 & -0.77 & 1.00 & \\
\hline$\alpha$-vetivone & -0.72 & -0.44 & -0.79 & 0.71 & -0.46 & 0.51 & 1.00 \\
\hline
\end{tabular}

\section{DISCUSSION}

\section{Molecular analyses with AFLP markers}

Various studies have demonstrated the efficient applicability of AFLP markers in Poaceae, as they have been used for both diversity analyses in handling germplasm banks and as a tool for mapping genes of interest for breeding. Performing molecular characterization of 
collections of corn, Netto et al. (2004) found a total of 207 AFLP loci in 58 genotypes using six primer combinations, with an average of 34.5 loci per combination. A total of 166 loci, of which 154 were polymorphic, were found in a genetic diversity study of eight oat individuals using seven primer combinations (Benin et al., 2008).

AFLP markers are dominant; however, they are more informative and reproducible than RAPD markers as they have the capacity to detect a large number of polymorphic bands in a single gel (Borém and Caixeta, 2009). Adams et al. (1998) performed a genetic diversity study of 23 vetiver accessions with RAPD markers using 13 primers, obtaining a total of 222 loci in the analyses. The results obtained in this study demonstrate the robustness and high level of information derived from the AFLP markers (442 loci with an average of 19.5 per primer combination) compared to studies of vetiver using RAPD markers, demonstrating that this method is efficient for the characterization of the diversity of this species. Thus, AFLP markers may be a better option for the evaluation of diversity and genetic relationships between corn lineages in comparison to RAPD markers. In addition to being very useful for mapping, they enable identification of genes of interest in Poaceae cultures, among other families, for breeding (Garcia et al., 2004).

The low genetic diversity index obtained in the current study may be due to, among other factors, the low number of individuals evaluated as well as the fact that vetiver is infertile, which contributes to the lack of allelic exchange between individuals. Additionally, vetiver is not native to Brazil and a similar study performed with RAPD markers by Adams et al. (1998) reported that vetiver plants have an elevated homozygosity when cultivated outside of their location of origin.

Genotypic diversity based on dominant data can be assessed using the Shannon index (I). This parameter measures the degree of uncertainty in predicting the genetic proximity between individuals, determining the richness and allelic uniformity. Additionally, it shows a relative advantage in studies with dominant markers as they are not based on heterozygosity and each marker is considered as a locus with two alleles. For this index, the closer the value is to zero, the lower the genetic diversity (Perry and Mcintosh, 1991). In the evaluated vetiver accessions, $I$ was equal to 0.32 (Table 3 ), with variation from 0 to 0.6931 for the loci, suggesting an average amplitude of diversity.

The population structure of the accessions was assessed by assigning individuals to groups (K) using a Bayesian approach, which was performed with the STRUCTURE program. This program uses an approach based on allelic frequencies to allocate the genotypes to each group (Pritchard et al., 2000a). $K$ values varying from 1 to 9 were tested, and the $\Delta K$ statistic from Evanno et al. (2005) showed $K$ values very close to 3 and 4. Considering this fact, Jakobsson and Rosenberg (2007) suggested that resampling be performed on the $K$ values obtained with as many repetitions as necessary to obtain the ideal $K$ value. Additionally, Pritchard et al. (2000b) indicated that the $K$ value should be chosen according to the most appropriate biological interpretation. Thus, $K$ equal to three was accepted for the discussion; this value was confirmed through resampling with the Clumpp program (Jakobsson and Rosenberg, 2007), which was consistent with the results obtained in the grouping analyses and the PCA.

The structuring analysis based on allelic frequencies differentiated the genotypes into three different groups, similar to the result obtained with the hierarchical grouping analyses, which are based on genetic distances. The inferences performed by STRUCTURE were shown to be sensitive in the separation of the genotypes, indicating the shared percentage of the genome and the proportion of ancestry between the accessions. This result indicates that 
the genotypes share alleles, which was corroborated in a study by Adams et al. (1998) who reported that the vetiver accessions distributed around the world derived from a single variety known as Sunshine.

Despite being a sterile plant with exclusively vegetative propagation, vetiver has vast utilization throughout the world. It is subject to factors, such as environmental variations, different types of planting, and multiple domestication events, in addition to adaptive processes of the species that can generate somatic mutations, contributing to the formation of ecotypes with genetic variability, as found in the accessions evaluated here.

The molecular characterization of accessions from the AGB of vetiver using AFLP markers was shown to be very satisfactory, providing information about the genetic variability between genotypes, in addition to separating the accessions into three genetically distinct groups.

\section{Chemical characterization of the essential oil}

Studies have demonstrated that vetiver roots have intracellular bacteria that associate with the cells that produce essential oil, performing the biotransformation of terpenes derived from the plants for the production of essential oil, with the composition of the oil potentially varying according to the microbial community (Adams et al., 2004; Del Giudice et al., 2008; Monteiro et al., 2009).

According to the dendrogram obtained using Euclidean distance for the chemical constituents present in the nine studied vetiver accessions, the genotypes UFS-VET001 (NatalRN) and UFS-VET007 (CENARGEN-DF) were the most divergent, with a distance of 7.63\%. The accessions UFS-VET005 (Natal-RN) and UFS-VET006 (Lavras-MG) were the most similar, with a distance of $1.33 \%$. Additionally, the two groups formed were not related to the location of origin of the accessions. A grouping analysis with a similar method was performed with Pogostemon sp. (Blank et al., 2011), which showed good consistency in the established chemical groups.

Khusimol, the most important constituent in the essential oil of vetiver, showed a strong and negative correlation with vetiselinenol (-0.88) and isovalencenol (-0.77). Massardo et al. (2006) found high concentrations of the compound isovalencenol (23.7\%) compared to the compound khusimol, which showed a lower average of $12.9 \%$. Additionally, the constituent khusimone showed a strong positive correlation with khusimol and a strong negative correlation with isovalencenol (-0.93) and vetiselinenol (-0.79).

In general, the dendrogram formed from the chemical constituents (Figure 5) is not related to the dendrogram established from the genetic divergences obtained for the nine vetiver accessions using the AFLP markers (Figure 2). The variation in the chemical composition of vetiver suggests that production of the different major constituents may be preferentially related to environmental factors, such as climate and temperature (Massardo et al., 2006), as well as the presence of symbiotic bacteria in the roots of the plant that actively participate in terpenoid metabolism (Adams et al., 2004; Del Giudice et al., 2008; Vollú et al., 2012). This hypothesis can be confirmed due to the fact that the accessions UFS-VET007 and UFS-VET008 showed high $(96 \%)$ genetic similarity but produced chemical constituents with significant differences (Table 6, Figure 2). Additionally, these genotypes are chemically grouped into distinct groups with a large distance between them (Figure 5), showing that the genome has little influence on the production of the chemical components present in the essential oil of vetiver.

It is important to emphasize that the production of the essential oil in medicinal and 
aromatic plants cannot be exclusively related to environmental factors, as the genetic makeup of the individuals must be taken into account. The genetic basis for the production of essential oil is not completely understood (Pichersky and Gang, 2000), and studies demonstrate that the production of essential oil in aromatic and medicinal plants may be associated with both the genotype and environmental factors (Blank et al., 2011). Thus, each aromatic plant species shows a set of chemical constituents that are activated according to physiological necessity, whether as mechanisms of attraction and defense against insects or to climate conditions.

The economic importance of vetiver has generated great interest in understanding the diversity of this species, an initial step for the selection and breeding of superior genotypes. Thus, the molecular and chemical characterization of the AGB of vetiver can provide information about the genetic variability so that the bank can be efficiently handled. Furthermore, individuals with promising and unique characteristics can be identified. Thus, molecular tools are essential in the characterization of the genetic diversity of aromatic and medicinal plants because, despite the agronomical and chemical characteristics that distinguish and group genotypes, the composition of the essential oils can be influenced by environmental factors. Additionally, the molecular data obtained in this study are very important, as they identify the diversity present in the accessions in addition to separating the accessions into three genetically distinct groups, which can be used in the selection of breeding programs of this culture.

\section{ACKNOWLEDGMENTS}

The authors thank FAPITEC/SE, CNPq, and CAPES for their financial support of this study. The authors also thank the RAROS Company for their support of conduction of the assay in field.

\section{Conflicts of interest}

The authors declare no conflict of interest.

\section{REFERENCES}

Adams RP (2007). Identification of essential oil components by gas chromatography/mass spectrometry. 4th edn. Allured Publishing Corporation, Carol Stream.

Adams RP, Zhong M, Turuspekov Y, Dafforn MR, et al. (1998). DNA fingerprinting reveals clonal nature of Vetiveria zizanioides (L.) Nash, Gramineae and sources of potential new germplasm. Mol. Ecol. 7: 813-818.

Adams RP, Habte M, Park S and Dafforn MR (2004). Preliminary comparison of vetiver root essential oils from cleansed (bacteria- and fungus-free) versus non-cleansed (normal) vetiver plants. Biochem. Syst. Ecol. 32: 1137-1144.

Alencar RG, Prado CC, Oliveira LMG, Freitas MRF, et al. (2005). Estudo farmacobotânico e fitoquímico da raiz de Vetiveria zizanioides L. Nash (vetiver). Rev. Elet. Farm. 2: 1-4.

Benin G, Carvalho FIF, Oliveira AC, Marchioro VS, et al. (2008). Morphological and AFLP markers for describing genetic relationships among white-oat genotypes. Bragantia 67: 563-568.

Blank AF, Sant'ana TCP, Santos PS, Arrigoni-Blank MF, et al. (2011). Chemical characterization of the essential oil from patchouli accessions harvested over four seasons. Ind. Crop. Prod. 34: 831-837.

Borém A and Caixeta ET (2009). Marcadores moleculares. 2nd edn. Folha de Viçosa, Viçosa.

Champagnat P, Figueredo G, Chalchat JC, Carnat AP, et al. (2006). A study on the composition of commercial Vetiveria zizanioides oils from different geographical origins. J. Essent. Oil Res. 18: 416-422.

Chomchalow N and Chapman K (2003). Other uses and utilization of vetiver. Assumption Univ. J. Technol. 7: 81-91.

Coelho ASG (2000). BOOD: Avaliação de dendrogramas baseados em estimativas de distancias/similaridades genéticas através do procedimento de bootstrap. UFG, Goiás. 
Del Giudice L, Massardo DR, Pontieri P, Bertea CM, et al. (2008). The microbial community of Vetiver root and its involvement into essential oil biogenesis. Environ. Microbiol. 10: 2824-2841.

Doyle JJ and Doyle JL (1990). Isolation of plant DNA from fresh tissue. Focus 12: 13-15.

Evanno G, Regnaut S and Goudet J (2005). Detecting the number of clusters of individuals using the software STRUCTURE: a simulation study. Mol. Ecol. 14: 2611-2620.

Ferreira DF (2010). SISVAR versão 5.3. Sistema de análise de variância para dados balanceados: Programa de análises estatísticas e planejamento de experimentos. Universidade Federal de Lavras, Lavras.

Ferreira ME and Grattapaglia D (1998). Introdução ao uso de marcadores moleculares em análise genética. 3rd edn. Embrapa Recursos Genéticos e Biotecnologia, Brasília.

Garcia AAF, Benchimol LL, Barbosa AMM, Geraldi IO, et al. (2004). Comparison of RAPD, RFLP, AFLP and SSR markers for diversity studies in tropical maize inbred lines. Genet. Mol. Biol. 27: 579-588.

Guenther E (1972). The essential oils, volume 3: individual essential oils of the plant families Rutaceae and Labiatae. 3rd edn. Krieger Publishing Company, Florida.

Jakobsson M and Rosenberg NA (2007). CLUMPP: a cluster matching and permutation program for dealing with label switching and multimodality in analysis of population structure. Bioinformatics 23: 1801-1806.

Kim HJ, Cheng F, Wang X, Chung HY, et al. (2005). Evaluation of antioxidant activity of vetiver (Vetiveria zizanioides L.) oil and identification of its antioxidant constituents. J. Agric. Food Chem. 53: 7691-7695.

Kimura M and Crow JF (1964). The number of alleles that can be maintained in finite population. Genetics 49: 725-738.

Lal RK (2013). On genetic diversity in germplasm of vetiver (Vetiveria zizanioides (L.) Nash). Ind. Crop. Prod. 43: 93-98.

Lerceteau E and Szmidt AE (1999). Properties of AFLP markers in inheritance and genetic diversity studies of Pinus sylvestris L. Heredity 82: 252-260.

Massardo DR, Senatore F, Alifano P, Del Giudice L, et al. (2006). Vetiver oil production correlates with early root growth. Biochem. Syst. Ecol. 34: 376-382.

Meyer AS, Garcia AAF, Souza AP and Souza CL (2004). Comparison of similarity coefficients used for cluster analysis with dominant markers in maize (Zea mays L.). Genet. Mol. Biol. 27: 83-91.

Mohammadi SA and Prasanna BM (2003). Analysis of genetic diversity in crop plants-salient statistical tools and considerations. Crop Sci. 43: 1235-1248.

Monteiro JM, Vollú RE, Coelho MRR, Alviano CS, et al. (2009). Comparison of the bacterial community and characterization of plant growth-promoting rhizobacteria from different genotypes of Chrysopogon zizanioides (L.) Roberty (vetiver) rhizospheres. J. Microbiol. 47: 363-370.

Nei M (1973). Analysis of gene diversity in subdivided populations. Proc. Natl. Acad. Sci. U.S.A. 70: 3321-3323.

Netto DAM, Souza IRP, Oliveira AC, Pinto CABR, et al. (2004). Avaliação agronômica e molecular de acessos da coleção núcleo de milho, subgrupo endosperma duro. Ver. Bras. Milho e Sorgo 3: 92-107.

Perrier X and Jacquermoud-Collet JP (2006). DARwin software. Available at [http://darwin.cirad.fr/darwin]. Accessed May 18, 2013.

Perry MC and Mcintosh MS (1991). Geographical patterns of variation in the USDA soybean germplasm collection: I. Morphological traits. Crop Sci. 31: 1350-1355.

Pichersky E and Gang DR (2000). Genetics and biochemistry of secondary metabolites in plants: an evolutionary perspective. Trends Plant Sci. 5: 439-445.

Pritchard JK, Stephens M and Donnelly P (2000a). Inference of population structure using multilocus genotype data. Genetics 155: 945-959.

Pritchard JK, Stephens M, Rosenberg NA and Donnelly P (2000b). Association mapping in structured populations. Am. J. Hum. Genet. 67: 170-181.

Van den Dool H and Kratz PD (1963). A generalization of the retention index system including linear temperature programmed gas-liquid partition chromatography. J. Chromatogr. A 11: 463-471.

Vollú RE, Blank AF, Seldin L and Coelho MRR (2012). Molecular diversity of nitrogen-fixing bacteria associated with Chrysopogon zizanioides (L.) Roberty (vetiver) an essential oil producer plant. Plant Soil 356: 101-111.

Vos P, Hogers R, Bleeker M, Reijans M, et al. (1995). AFLP: a new technique for DNA fingerprinting. Nucleic Acids Res. 23: 4407-4414.

Yeh FC, Yang RC and Boyle T (1999). POPGENE, version 1.31. Microsoft Window-based freeware for population genetic analysis. University of Alberta, Edmonton.

Zhu BCR, Henderson G, Chen F, Fei H, et al. (2001). Evaluation of vetiver oil and seven insect-active essential oils against the Formosan subterranean termite. J. Chem. Ecol. 27: 1617-1625. 